\title{
Understanding the inner workings of the research-teaching nexus in Taiwan higher education
}

\author{
$\mathrm{Hu}$, Yueh-Luen
}

Department of Education, National Chengchi University, Taiwan (joyhu@nccu.edu.tw)

Ching, Gregory S.

Graduate Institute of Educational Leadership and Development, Fu Jen Catholic University, Taiwan (gregory_ching@yahoo.com; 094478@mail.fju.edu.tw)

Hung, Chao-Hsiang

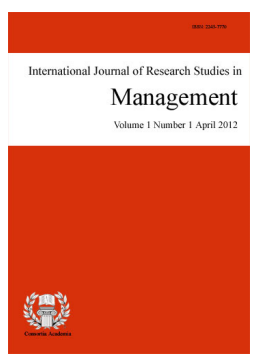

ISSN: $2243-7770$ Online ISSN: 2243-7789

OPEN ACCESS

Department of Education, National Chengchi University, Taiwan (ka0518@gmail.com)

\section{Abstract}

Competition in higher education has forced universities to push for excellence. This phenomenon of pushing for excellence has caused institutions to focus more on research rather than teaching. With the evolving nature of higher education, what matter most is to strike a balance between research and teaching activities. To answer this question, the current study adapted the Changing Academic Profession (CAP) (Teichler, Arimoto, \& Cummings, 2013) survey and collected data from the Career and professional situation, General work situation and activities, Teaching, Research, and Management situations of faculties in Taiwan higher education institutions. Data was collected from 457 faculties from 18 universities. Results show that Taiwan higher education institutions practices gender equality, while having a diverse concepts on international mobility. It is also noted that financial compensations are moderately comparable with other previous CAP surveyed countries. Sadly, results show that Taiwan higher education institution faculties have long working hours with moderate to high perceived stress. Lastly, discriminant analysis shows that individuals with high degree of disciplinary affiliations tend to have research collaborations and have the tendency to publish more than their peers. It is hoped that by better understanding how faculty preferences affects their work situation and performance, policy recommendations can be made in promoting a more balance research and teaching nexus in the academe.

Keywords: research teaching nexus; time budget; institutional policy; higher education; disciplinary affiliation; collaboration; research performance 


\section{Understanding the inner workings of the research-teaching nexus in Taiwan higher education}

\section{Introduction}

Current higher education atmosphere is containing both competition and collaboration (Baty, 2017). This situation is mostly brought upon by the continued impact of the so-called global university rankings or higher education league tables (Hazelkorn, 2011; Holmes, 2013; Luxbacher, 2013). In reality, this increased competition is not new (Trow, 1974). Starting from the early eighties, higher education expansion has never cease to elicit competitions among universities (Guri-Rosenblit, Sebkova, \& Teichler, 2007). This expansion and change of HEI's mission or more commonly referred to as mission creep; is the phenomenon wherein institutions readily adapts to the environment and expand towards the direction with the most possible gains (Longanecker, 2008). However, such expansion of an institution's mission or creeping comes at a significant cost. Many HEIs have started to emphasized more on research productivity than teaching (Gumport, 2000; Subramaniam, Perrucci, \& Whitlock, 2014). In effect, this creeping has led to the highly debatable issues of the research and teaching activities within higher education institutions (Arimoto, 2014).

For higher education institutions, focusing on either research or teaching is like treading on dangerous waters. This concern was initially proposed by Boyer (1990), wherein he felt that the effects of higher education's expansion and increased emphasis on research productivity would eventually affect academic work. This in fact laid the ground work for the Carnegie International Survey of the Academic Profession (Altbach, 1996; Boyer, Altbach, \& Whitelaw, 1994) and the Changing Academic Profession (CAP) (Teichler et al., 2013). The CAP project was accomplished from 2004 to 2012 with the assistance of more than 100 scholars from 19 countries. With this having said, CAP is seen as one of the key influential players in recent global higher education policy changes within the academic profession. Building on such premise, it is therefore, the primary goal of this study to determine and understand how higher education faculty in Taiwan balances their research and teaching activities.

\section{The changing academic profession}

Quoting Teichler (2013) and his colleagues: the academic profession is often portrayed as composed of persons strongly driven by intrinsic motives who concentrate primarily on the substance of teaching and research (p. 75). With this having said, one can assumed that the role of the faculty is to teach and to do research. In reality, the role of the academic profession has been changing over time. According to Arimoto (2014), there have been three major shifts or changes within the academic profession, which are highly correlated with the evolution of universities; more specifically, from the pre-modern (medieval) to modern, and to the post-modern (future) university (p. 15). These changes are responses on how society has changed over time, from the early agricultural to the later industrial, and to the most recent knowledge-based economy.

History shows that within the early $12^{\text {th }}$ century, the pre-modern universities emerge; these are mostly in the form of informal schools scattered all over Europe (Scearce, 2008). Lasting for about six centuries, universities during that time are mostly focused on academic teaching. Later on, in the $19^{\text {th }}$ century, the modern universities were born. These institutions are focused on both academic research and teaching (Altbach, 2011). Then on, the current post-modern or future university emerges focusing more on student learning (Arimoto, 2014).

Within the above mentioned three different perspectives of higher education institutions, three different types of universities also emerge. Accordingly, the academic profession also changes coincide along with the transformation of universities. During this transition, initial teaching only pre-modern universities are later transformed to include research. The role of the faculty, teacher, or academic staff was expanded to encompassed 
a researcher within their own area of discipline (Arimoto, 2014). This transformation also included the expansion of universities, as noted by Trow (1974) with the rise in numbers of various types of institutions (some referred to as non-university sector, such as junior colleges, in general terms can be considered as HEIs). One noteworthy feature of the modern university is the increasing universality of higher education, which is said to be competing with the university in terms of teaching, as the student population is becoming increasingly massified and diverse (Arimoto, 2014, p. 16).

Within the post-modern or future universities, the link between research and teaching are seen as important aspect of the student learning process (Healey, 2005). The transition of the teacher-centered to student-centered instruction has all together changed the concepts of learning (Hannafin, Hill, Land, \& Lee, 2014; Jonassen \& Easter, 2012; Land, Hannafin, \& Oliver, 2012). Therefore, within future universities, faculty focuses more on students as learners, more specifically at the undergraduate levels (as opposed to that of the graduate programs within the previous modern universities) (Arimoto, 2014). In sum, as the role of faculty evolved along with the transformation of the university, it is therefore highly important to balance the research and teaching activities of teachers in order to create a healthy profession.

\section{Disparities within the changing academic profession}

As mentioned before with the massification of higher education, dynamic changes have been happening. These changes have caused various disparities in both the intra-national and cross-national front (Hu, Hung, \& Ching, 2016). CAP results mentioned the various disparities in the preferences and actual research hours of faculty in different countries and university types. For instance, results show that there seems to be a consistent higher research preference within the faculty of research type universities as compared to the other HEIs within their own system. Generalizing that majority of the faculty within research universities has stronger research preferences and use more of their time in doing research than teaching (Cummings \& Shin, 2014). These disparities actually form the contrasting arguments that hinder the proper functioning of the academic work. Therefore understanding such disparities would surely be able to provide insightful information that would lead to better future policy initiatives. The following section shall describe in brief inequalities within the contemporary higher education academe.

\subsection{Gender disparity}

As with the traditional notion of more males than females in higher education, currently there is a noted reversal of such situation (Grebennikov \& Skaines, 2009; Vincent-Lancrin, 2008). However, within the composition of higher education faculty, different education systems have shown various disparities among their faculty makeup (Teichler et al., 2013). The CAP survey shows that the highest share of female professors at core and semi-periphery system countries is around $40 \%$ (Australia with 39\%, UK with 33\%, and the US with 32\%), while slightly lower (around one-fifth) of the female professors are found in Hong Kong with $20 \%$, the Netherlands with 19\%, Germany with 18\%, Japan and Korea with both 13\%. Interestingly, periphery developing countries have a higher composition of female faculty such as in South Africa with $46 \%$ and Brazil with $45 \%$ with the rest having slightly less than $40 \%$ female faculty.

The gender disparity is not only found in different countries, but is also present in the different faculty levels. In most of the CAP surveyed countries, the share of female junior faculty (assistant professors and lower) comprises more than half of the workforce in Australia with 63\%, Argentina with 54\%, UK and China with 52\%, and in Norway with 50\%, while, Germany with 38\%, the Netherlands with 35\%, Korea with 20\%, and Japan with $14 \%$ seemingly following their trend of fewer female faculty. Similar disparities are also found in the different types of HEIs (such as gender disparities within technical and vocational universities). Noting the cause of such gender disparity might be correlated with the nature of academic discipline, wherein most male oriented field in engineering comprises much of the technical and vocational universities (Clark, 2013; Teichler et al., 2013). 
In sum, there is indeed a lower proportion of female faculty in senior positions than at the lower junior positions within HEIs, denoting a lower share of female faculty moving up to the higher stages of the career ladder. This gender disparity is also quite often connected to career selectivity according to gender in many countries (Teichler et al., 2013). More important, a comparison of the results of the Carnegie International Survey of the Academic Profession and CAP survey showed that there are some striking increases (more than doubled) in terms of female representations in some countries such as in Australia from 10\% in 1992 to 39\% in 2007, UK from 6 to 33\%, Germany from 6 to 18\%, the Netherlands from 8 to 19\% and Japan from 1 to 13\% respectively, have been observed. However, even though that there are significant increases in recent survey results, in reality these increases still did not reflect gender equality among the composition of the faculty.

\subsection{Disparity in qualifications}

For a long time now, a $\mathrm{PhD}$ degree seems to be the normal entry qualification for a career in higher education (Teichler et al., 2013). A comparison of the results of the Carnegie International Survey of the Academic Profession and CAP survey showed many disparities. No change was seen in Germany and Japan, which stays at a constant of $95 \%$ and $85 \%$ respectively, for new faculty having a PhD degree from the 1992 survey to the 2007 survey. It is noted that in Germany, before a faculty could be promoted to professorship, he/she should have passed the habilitation; a kind of second-level doctoral degree, as a requirement for eligibility as a professor (Hairston, 2013; Schiewer, Jehle, \& Maes, 2014). While, a decrease was seen in the US from 94 to $91 \%$ and the Netherlands from 90 to $83 \%$; interestingly, a small increased was seen in the UK from 74 to $78 \%$, while a large increased was observed in Korea from 79 to $99 \%$, Hong Kong from 80 to $94 \%$, and Australia from 85 to $92 \%$ respectively.

As with the disparity in the requirement of a $\mathrm{PhD}$ degree would be partially caused by the difference with the amount of time (years before graduation) it take to finish doctoral education (Garibaldi, Giavazzi, Ichino, \& Rettore, 2012; Jazvac-Martek, Chen, \& McAlpine, 2011; Stock, Siegfried, \& Finegan, 2011). The CAP survey shows that the average $\mathrm{PhD}$ graduation age is 30 years old in Germany, 31 years old in UK, and 32 years old in Italy. While some are typically high, such as 35 years old in China, 36 years old in Malaysia and Finland, 37 years old in Norway and South Africa, 38 years old in Brazil, and 40 years old in Argentina and Mexico. Such disparities in entry qualifications, in a sense determines the number of years wherein a faculty can be productive as contrast to the years needed in securing a doctoral degree. As noted by many that the early academic profession is composed of long periods of concurrent learning and productive work and often accompanied by relatively limited financial gains (Teichler et al., 2013, p. 75).

\subsection{Disparity in professional and institutional mobility}

Recent debates in the issues regarding the need for faculty to have previous experience in the industry (Tartari, Salter, \& Este, 2012) and the need for having courses that need the collaboration of the industry (Goldberg, Cariapa, Corliss, \& Kaiser, 2014) are increasing. Actually, most faculties would spend their entire career within higher education. Scholars think that being employed their entire career within one single institution would often be viewed as an honor or having a sense of pride, however, this concept might also be thought of as a negative form of inbreeding (Teichler et al., 2013, p. 82).

Inbreeding is defined as the situation wherein PhDs are employed in the very same institution that trained them during their doctoral studies (Inanc \& Tuncer, 2011, p. 885). The definition of inbreeding also encompasses the situation, wherein an individual since graduation, has been employed entirely by a single HEI (Teichler et al., 2013, p. 82). Studies have shown that older universities tend to practice inbreeding (Tavares, Cardoso, Carvalho, Sousa, \& Santiago, 2014), some even noted that inbreeding as a sort of tradition in assuring organizational stability and institutional identity (Horta, Sato, \& Yonezawa, 2010) (typically found in Japanese universities). Although some studies have shown that there are no significant negative impact of inbreeding in the productivity of a department (Smyth \& Mishra, 2014), however, excessive practice of inbreeding is said to 
Understanding the inner workings of the research-teaching nexus in Taiwan higher education

have adversely affects the overall productivity (Inanc \& Tuncer, 2011). Within some studies, there are actually contrary suggestions for the need of mobility in academic careers (Horta, 2013).

With respect to the CAP results, Germany and the US show the highest inter-university mobility of professors. More interesting are the countries that seem to practice faculty inbreeding such as China with $70 \%$, Portugal with 64\%, and Italy with 48\%. A comparison of the results of the Carnegie International Survey of the Academic Profession and CAP survey, in most cases a decrease was observed (besides the aforementioned countries), such as in Japan from 56 to 30\% and the US from 41 to 13\% respectively. In sum, the professional and institutional mobility of faculty are seen as a very controversial issue. Hence, there is also a need for further understanding of the current situation and their corresponding effects in Taiwan HEIs.

\subsection{Disparity in employment conditions and income}

Currently, there is a substantial number of junior faculty that are employed as part-time basis (Teichler et al., 2013, p. 88), while almost all senior professors are employed full-time. This phenomenon is said to be caused by the market-driven forces under the influence of the managerial university (Finkelstein, 2010). Results in the CAP survey showed varied employment conditions. Typically low part-time faculty is found in Korea with no part-time faculty at all, Malaysia with $1 \%$, China, Canada, and Italy with $2 \%$, South Africa with $3 \%$, and Finland and Mexico with 6\%. A comparison of the results of the Carnegie International Survey of the Academic Profession and CAP survey shows a substantial increase was found in Japan from 2 to $7 \%$ and contrastingly a decrease in Hong Kong from 26 to $10 \%$ respectively. However, disparities within employment conditions is quite common with the diverse employment practices of different systems (Teichler et al., 2013, p. 91). Even more controversial is the disparity of income, in reality, the academic profession is considered as not being as highly paid as compared to other professions, such as doctor and lawyers. In essence, understanding the employment conditions and income of faculty as compared with other countries should be able to provide valuable policy inputs that are key to future advances in the academic profession in Taiwan.

\subsection{Disparity among the degree of faculty affiliations with their institution and discipline}

As mentioned before, during the modern university, faculty tends to bond together within their specific disciplines, such as mathematics, history, physics, and many others. This is accomplished in order to pursue research, teaching, service, and further development the field of study (Parry, 2007). Hence, faculty easily formed an identity based on their relationship to the academic discipline. This would actually start when an individual select their graduate course discipline. To prove this point, during the CAP survey, results show that around $60 \%$ of the surveyed faculty noted their affiliation to their discipline as very important, $34 \%$ to their department, and almost similar 33\% with their institution. CAP result seems to denote that upon given the opportunity and appropriate motivation, faculty would tend to shift institutions as long as the nature of the academic work is still within the same discipline. Alliances to the discipline are stronger than the alliances to the department and institutions.

\subsection{Disparity in time budget}

As mentioned in the earlier sections, there exists a disparity among the actual working hours of faculty. A typical scenario in advanced countries is seen as faculty strongly devoting to their work task and spends more time for academic work than they are officially required to. While, in some developing countries, low income in higher education forces considerable extra moonlighting at the expense of work time (Teichler et al., 2013, p. 98). More important, is the debate with the proper amount of time spent on dealing with administrative matters, while sacrificing the time devoted to research and teaching.

\subsection{Disparity in the number of students enrolled within a specific field of study}

Academic scholars would view the strength or prestige of a department depending on the number of faculty 
and the quality of the facilities (Cummings \& Shin, 2014). However, for school administrators, it all falls to the number game; which means that the number of enrolled students counts the most. Hence, tension arises wherein discipline of studies that are once famous and are now declining. For instance, recent news have varied notion with regards to the decreasing number liberal arts colleges in the US (Baker, Baldwin, \& Makker, 2012; Jaschik, 2012, 2014a), while statistics have shown that science, technology, engineering, and mathematics (STEM) students are at an all-time high (Jaschik, 2014b). This is also quite true in Taiwan, wherein various news of transforming department (or changing their name) and even the closing of English and Philosophy departments from lack of students, are quite disturbing. As marketization of higher education is inevitable (D.-F. Chang, Wu, Ching, Tang, \& Hsiao, 2010), in order for HEIs to survive financial considerations and decisions are unavoidable. Therefore, a healthy research-teaching combination within low performing departments should be able to help revive the department.

With the various disparity found within the contemporary HEIs are much inter-related with each other, it would also seem that the challenges for having a healthy academic profession is far from attainable. Therefore, before any policy initiatives can be accomplished, a thorough understanding of current higher education situation is a must. As for the current study, focus were made on how faculty in Taiwan higher education balanced their research and teaching activities, while taking into account the various aspects of disparities within the evolving academic profession.

\section{Methodology}

The current study is anchored on the highly cited framework for comparative education analysis proposed by Bray and Thomas (1995), wherein a three-dimensional cube with three distinct sides, namely: Geographical location levels, aspects of education and society, and non-locational demographic groups as focal points of comparison. For studies that are explicitly comparative in nature, which tend to engage all of the three dimensions. Hence, the three dimensional map provides a clear point of comparison (Bray, Adamson, \& Mason, 2007). For the current study, it is noted by using a multi-level (multi-dimensional) analysis such as intra-national (local nationwide) and cross-national (across countries, as noted in the previous discussions within the literature review) are quite helpful in providing a clearer and accurate picture of the issues being compared, such as the changing academic profession in Taiwan.

To collect the data, a revised questionnaire based on the previous CAP study (Teichler et al., 2013) were utilized. Similar strands of information were based on the original CAP survey which is primarily composed of six sections, namely: Career and professional situation, which includes questions regarding professional background information such as course major, work history and many others. General work situation and activities, which includes questions regarding the professional work done within a typical week such as time spent on teaching and research and job satisfaction. Teaching includes questions regarding the current academic responsibilities. Research includes questions regarding the current academic responsibilities. Management includes questions regarding the institution wherein the faculty works. Lastly, personal demographical backgrounds are also asked. During the CAP implementation, it is also suggested that each country would customize the content to an extent that it would reflect more a local perspective, however, without losing its international comparability.

Collection of data started on the fall semester of 2016, an invitation to participate in the survey was send to strategically selected participants from 18 universities. Among the 800 invitations, a total of 457 valid responses were collected or having a 57\% return rate. Data analysis includes the various descriptive statistics for the participants' demographics and discriminant analysis to determine if there are any distinct clusters or groups that can differentiate research and teaching activities (McLachlan, 2004).

Within the 457 valid returns, a total of 311 or $68 \%$ are male faculty with a mean age of 47 years old, while the remaining 146 or $32 \%$ are female faculty with a mean age of 45 years old (see Table 1). Furthermore, it is 
Understanding the inner workings of the research-teaching nexus in Taiwan higher education

also noted that among the respondents there are around 105 or $23 \%$ junior and 352 or 77 senior faculties. While, 165 or $36 \%$ works in public universities and 292 or $64 \%$ are employed by private institutions. Lastly, as for the field of studies, a total of 165 or $36 \%$ are with the nature science and 292 or $64 \%$ are with the social science and humanities.

Table 1

Respondents' gender and age $(N=457)$

\begin{tabular}{|c|c|c|c|}
\hline Respondents & $n$ & $\%$ & Mean Age \\
\hline Male & 311 & 68 & 47 \\
\hline Female & 146 & 32 & 45 \\
\hline Total & 457 & 100 & 46 \\
\hline
\end{tabular}

Table 2

Respondents' characteristics $(N=457)$

\begin{tabular}{lccc}
\hline \multicolumn{2}{c}{ Characteristics } & $n$ & $\%$ \\
\hline \multicolumn{2}{c}{ Status } & 105 & 23 \\
Junior faculty & & 352 & 77 \\
Senior faculty & & \\
\multicolumn{2}{c}{ Institution } & 36 & 165 \\
Public & & 64 & 292 \\
Private & Field & 36 & 165 \\
Nature Science & & 292 \\
Social Science and Humanities & 64 & \\
\hline
\end{tabular}

\section{Results and discussions}

\subsection{Disparities among gender}

Looking into the overall statistics within the Taiwan Ministry of Education Statistics information (https://english.moe.gov.tw/cp-28-14508-95005-1.html), it is well noted that within senior faculties, there is an equal distribution of gender with having $\mathbf{5 0 \%}$ coming from both male and female. This figure is highest among the previous CAP results (Teichler et al., 2013, p. 79). However, as for the junior faculties, national statistical data shows that female make up around $41 \%$ of the entire pool. This result is somewhat disturbing, since after 10 years, these junior faculties would become senior and affect the future gender distributions.

\subsection{Disparities among international mobility}

Analysis of faculty mobility started as early in the 1970s, wherein findings suggest that among junior faculties, prestige of their $\mathrm{PhD}$ program is more crucial than looking into their past performance (Crane, 1970). For the current study (and similar with the CAP study), international mobility is measured whether the respondent's citizenship is different with the current country of residence, at birth (indicating migration), and at the moment of receiving the first degree (Teichler et al., 2013). Results from the collected data indicate that around $\mathbf{6 3 \%}$ of the senior and $\mathbf{7 4 \%}$ of the junior faculty respondents shows indication of international mobility. This result is quite interesting, wherein comparison from the CAP results, Taiwan shows the highest international mobility (see Teichler et al., 2013, p. 86). In reality this might be consider as both having positive and negative implications. Positive meaning that faculties are quite internationalized with many acquiring their degrees outside of Taiwan. However, negative meaning that homegrown doctoral students are having a hard time in securing a teaching position locally.

Within another spectrum of international mobility, CAP also looks into both the medium of instructions and medium of academic publications. Results of the survey show that around $2 \%$ of the senior and $4 \%$ of the junior 
Hu, Y.-L., Ching, G. S., \& Hung, C.-H.

faculty respondents used foreign language as their medium of instruction. This result is quite low in comparison with the CAP results (Teichler et al., 2013, p. 87), indicating the low internationalization of the course offerings in Taiwan higher education institutions. As for the language medium for academic publications, results of the survey show that around $\mathbf{3 7 \%}$ of the senior and $\mathbf{3 5 \%}$ of the junior faculty respondents used foreign language as their medium of publication (presumably English), indicating quite moderate results when in comparison with the previous CAP results (Teichler et al., 2013, p. 87). This also implicates the importance in international publications as compared to local ones. Furthermore, upon classification is perform in terms of field domains, results show that the social sciences and humanities are more concentrated in publishing with the use of local language.

Table 3

Medium of publication in various field domains $(N=457)$

\begin{tabular}{lcccc}
\hline \multirow{2}{*}{ Field } & \multicolumn{2}{c}{ Local language } & \multicolumn{2}{c}{ Foreign language } \\
\cline { 2 - 5 } & $n$ & $\%$ & $n$ & $\%$ \\
\hline Nature Science & 236 & 52 & 221 & 48 \\
Social Science and Humanities & 324 & 71 & 133 & 29 \\
\multicolumn{1}{c}{ Total } & 292 & 64 & 165 & 36 \\
\hline
\end{tabular}

\subsection{Disparity among employment conditions and income}

Previous studies have noted that higher education employment conditions are quite related to their performance (Bowen \& Schuster, 1986; Kezar \& Sam, 2010). CAP results show that within a five point scale (1-excellent to 5-poor) of having average (ratings of 2.2 to 3.1) satisfactions (Teichler et al., 2013, p. 95). For the current study, respondents have shown to have around 2.4 for the senior and 2.6 for the junior faculties, denoting somewhat similar trend of employment conditions. However, in terms of financial compensation, results of the survey noted senior faculties earned around 40,000 US dollars annually, while junior faculties earned around 30,000 US dollars annually, denoting average compensations as compared to other CAP results (Teichler et al., 2013, p. 93).

\subsection{Disparity in time budget}

For the weekly working hours, results of the survey shows that senior faculties worked around $\mathbf{5 3}$ hours a week, while junior faculties worked around $\mathbf{4 4}$ hours per week. These results are quite high as compared to the previous CAP results (second only after South Korea) (Teichler et al., 2013, p. 100). In comparing with the overall self-assessed employment as a source of personal strain, results of the survey show that around $\mathbf{6 2 \%}$ of the senior and $\mathbf{6 5 \%}$ of the junior faculty respondents confirmed that they perceived higher education work is quite stressful (Teichler et al., 2013, p. 108). Note the highly stressful indications for Asian systems.

\subsection{Disparity in research - teaching preferences}

For the disparities within the research and teaching preferences, results show that respondents classified themselves within four groups, namely: mostly teaching, teaching inclination, research inclination, and mostly research. Taking note that majority of the respondents falls within either the teaching or research inclination, suggesting that they would prefer more on doing research or teaching while not totally relinquishing on teaching or research. Table 4 shows that junior faculties need to do both, while senior faculties could slightly focused on their teaching. As for the field domain specific, the nature science groups are mostly concentrated on doing research, while the social sciences and humanities are in teaching. Lastly, teachers who work in private universities are more likely to be doing more teaching, as compared to doing more researches for the faculties who worked in the public or national institutions.

Table 5 shows the self-reported weekly hours of focusing on research and teaching. Results are quite 
Understanding the inner workings of the research-teaching nexus in Taiwan higher education

surprising, that even though respondents classified themselves as inclined more on teaching, in reality, their weekly hours of doing research is similar with their time spend on teaching. As for the respondents who classified themselves as inclined to doing research, results show that they are actually teaching 2 hours more than the teaching inclined respondents (16 as compared to 14 hours), while also devoting to 22 hours of research per week.

\section{Table 4}

Self-reported research-teaching preferences $(N=457)$

\begin{tabular}{lcccccc}
\hline \multicolumn{1}{c}{ Preference } & Junior & Senior & Nature & Soc. Sci. & Private & Public \\
\hline Mostly teaching & 13.5 & 13.3 & 5.7 & 17.6 & 17.4 & 6.2 \\
Teaching inclination & 43.8 & 45.1 & 38.2 & $\mathbf{4 6 . 4}$ & $\mathbf{4 6 . 5}$ & 39.5 \\
Research inclination & 41.7 & 39.3 & $\mathbf{5 2 . 9}$ & 34.5 & 34.8 & $\mathbf{5 1 . 2}$ \\
Mostly research & 1.0 & 2.3 & 3.2 & 1.4 & 1.4 & 3.1 \\
\hline
\end{tabular}

Note. Values are in percentage of respondents.

\section{Table 5}

Time spent on activities $(N=457)$

\begin{tabular}{lcc}
\hline \multicolumn{1}{c}{ Preference } & Teaching & Research \\
\hline Teaching inclination & 14 & 14 \\
Research inclination & 16 & 22 \\
\hline Note. Values are in hours per week. & &
\end{tabular}

For the discriminant analysis, three variables were included in the computation, namely disciplinary affiliation, co-primary investigator, and the number of publication in academic journals and books. Disciplinary affiliation is encoded with 0 meaning low, while 1 denoting high degree of affiliation. For the co-primary investigator, respondents select either 1 with having research collaborations and 0 with having no research collaborations. Table 6 shows the result of the discriminant analysis with eigenvalue of .232 and Wilks' Lambda of $.812(p<.001)$ denoting significant classifications with overall variance explained of $70.6 \%$. In sum, as respondents who have a high degree of disciplinary affiliations tends to have research collaborations and in return will also have higher number of publications.

\section{Table 6}

Discriminant analysis on the research-teaching preferences $(N=457)$

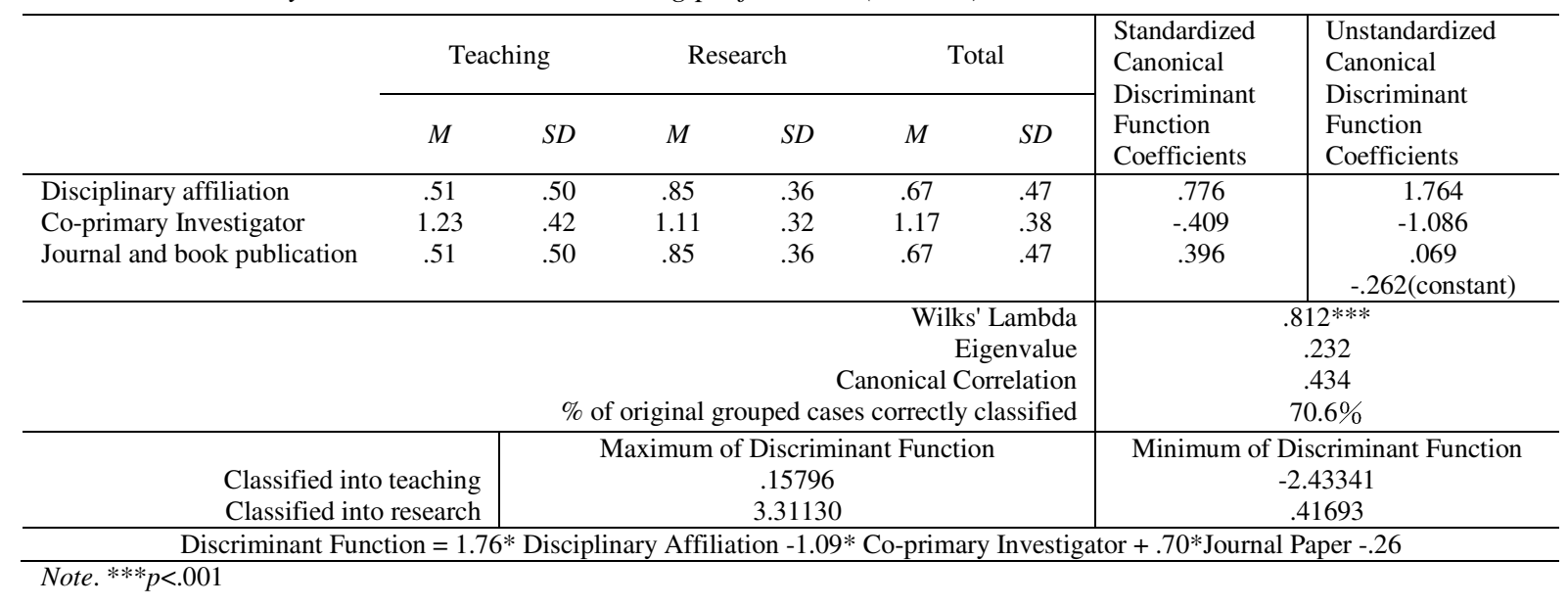

\section{Conclusions}

The research and teaching balance is not impossible but a challenge. Within the higher education institutions in Taiwan, the academic profession is quite diverse. This can be seen in various differences emerging from either the senior with the junior faculties, either teaching in a public or the private institutions, and together with the 
difference types of academic field domains of nature science and social science and humanities. The current study depicted the various disparities in contrast with the previous results collected from the CAP survey. Interestingly, a phenomenon common to Asian systems, Taiwan higher education is focused on publishing academic works in journals indexed in citation databases (Ching, 2013a, 2013b), which in most cases are in English. Hence, why an inconsistencies exists between the medium of instructions and language used in academic publications. As for the for the faculties who worked in either the public or private universities, studies have shown that private institutions in Taiwan are more focused on teaching as compared to their public counterparts (T.-S. Chang, Lin, \& Song, 2011). This can be seen with the disparities found in connection with the faculty working hours. Furthermore, As the fact that academic performance is mostly measured in academic publications (Huang, Chang, \& Chen, 2006; Kao \& Pao, 2009), many faculties are quite over worked and considers the profession a highly stressful occupation. Lastly, with the differences with the academic fields also offers various disparities, due to the fact that the nature science field is more internationalized as compared to social sciences and humanities, which is a more local in focus (Wen, Ching, \& Tang, 2013). Therefore, academic publications and medium of instructions also differs greatly. It is hoped that by better understanding how faculty preferences affects their work situation and performance, policy recommendations can be made in promoting a more balance research and teaching nexus in the academe.

Acknowledgements: This study is sponsored by the Taiwan Ministry of Science and Technology (MOST 104-2410-H-004-151-SS2). An earlier version of this paper is also accepted for presentation in the upcoming International Conference on Education, Teaching, and Learning in Hong Kong on August 1-2, 2018.

\section{References}

Altbach, P. G. (2011). The past, present, and future of the research university. In P. G. Altbach \& J. Salmi (Eds.), The road to academic excellence: The making of world-class research universities (pp. 11-32).

Washington, DC: The World Bank. https://doi.org/10.1596/9780821388051_CH01

Altbach, P. G. (Ed.). (1996). The international academic profession: Portraits of fourteen countries. Princeton: Carnegie Foundation.

Arimoto, A. (2014). The teaching and research nexus in the third wave age. In J. C. Shin, A. Arimoto, W. K. Cummings \& U. Teichler (Eds.), Teaching and research in contemporary higher education: Systems, activities and rewards (pp. 15-33). Dordrecht: Springer. https://doi.org/10.1007/978-94-007-6830-7_2

Baker, V. L., Baldwin, R. G., \& Makker, S. (2012). Where are they now? Revisiting Breneman's study of liberal arts colleges. Retrieved from

https://www.aacu.org/publications-research/periodicals/where-are-they-now-revisiting-brenemans-study -liberal-arts

Baty, P. (2017). World university rankings: Boosting both competition and collaboration. Retrieved from https://www.timeshighereducation.com/blog/world-university-rankings-boosting-both-competition-andcollaboration

Bowen, H. R., \& Schuster, J. H. (1986). American professors: A national resource imperiled. Fair Lawn, NJ: Oxford University Press.

Boyer, E. L. (1990). Scholarship reconsidered: Priorities of the professoriate. Princeton: Carnegie Foundation.

Boyer, E. L., Altbach, P. G., \& Whitelaw, M. J. (1994). The academic profession: An international perspective. Princeton: Carnegie Foundation.

Bray, M., Adamson, B., \& Mason, M. (2007). Introduction. In M. Bray, B. Adamson \& M. Mason (Eds.), Comparative education research: Approaches and methods (pp. 1-11). Hong Kong: Comparative Education Research Centre. https://doi.org/10.1007/978-1-4020-6189-9

Bray, M., \& Thomas, R. M. (1995). Levels of comparison in educational studies: Different insights from different literatures and the value of multilevel analysis. Harvard Educational Review, 65(3), 472-490. https://doi.org/10.17763/haer.65.3.g3228437224v4877

Chang, D.-F., Wu, C.-T., Ching, G. S., Tang, J.-W., \& Hsiao, L. (2010). Globalization and higher education in Taiwan. In P. Pachura (Ed.), New knowledge in a new era of globalization (pp. 35-48). Croatia: Intech.

Chang, T.-S., Lin, H.-H., \& Song, M.-M. (2011). University faculty members' perceptions of their teaching efficacy. Innovations in Education and Teaching International, 48(1), 49-60. 
Understanding the inner workings of the research-teaching nexus in Taiwan higher education

https://doi.org/10.1080/14703297.2010.543770

Ching, G. S. (2013a). ISI perceptions and hard facts: An empirical study from Taiwan. In C. P. Chou (Ed.), The SSCI syndrome in higher education: A local or global phenomenon (pp. 81-92). Rotterdam, The Netherlands: Sense Publishing.

Ching, G. S. (2013b). Unraveling issues behind ISI misconceptions: An empirical study on the practical effects of academic publication. International Journal of Research Studies in Education, 2(3), 51-64. https://doi.org/10.5861/ijrse.2012.288

Clark, E. (2013). Gender diversity among higher education CIOs. Retrieved from https://net.educause.edu/ir/library/pdf/ERS1311.pdf

Crane, D. (1970). The academic marketplace revisited: A study of faculty mobility using the Cartter ratings. American Journal of Sociology 75(6), 953-964. https://doi.org/10.1086/224848

Cummings, W. K., \& Shin, J. C. (2014). Teaching and research in contemporary higher education: An overview. In J. C. Shin, A. Arimoto, W. K. Cummings \& U. Teichler (Eds.), Teaching and research in contemporary higher education: Systems, activities and rewards (pp. 1-12). Dordrecht: Springer. https://doi.org/10.1007/978-94-007-6830-7_1

Finkelstein, M. J. (2010). Diversification in the academic workforce: The case of the US and implications for Europe. European Review, 18(Supplement 1), 141-156. https://doi.org/10.1017/S1062798709990366

Garibaldi, P., Giavazzi, F., Ichino, A., \& Rettore, E. (2012). College cost and time to complete a degree: Evidence from tuition discontinuities. The Review of Economics and Statistics, 94(3), 699-711. https://doi.org/10.1162/REST_a_00195

Goldberg, J. R., Cariapa, V., Corliss, G., \& Kaiser, K. (2014). Benefits of industry involvement in multidisciplinary capstone design courses. International Journal of Engineering Education, 30(1), 6-13.

Grebennikov, L., \& Skaines, I. (2009). Gender and higher education experience: A case study. Higher Education Research \& Development, 28(1), 71-84. https://doi.org/10.1080/07294360802444370

Gumport, P. J. (2000). Academic restructuring: Organizational change and institutional imperatives. Higher Education, 39(1), 67-91. https://doi.org/10.1023/A:1003859026301

Guri-Rosenblit, S., Sebkova, H., \& Teichler, U. (2007). Massification and diversity of higher education systems: Interplay of complex dimensions. Higher Education Policy, 20(4), 373-389. https://doi.org/10.1057/palgrave.hep.8300158

Hairston, C. C. (2013). Impact of the Bologna process and German higher education reforms on professorial work and role definition at the University of Postdam: A case study. Unpublished Doctoral Dissertation.

Hannafin, M. J., Hill, J. R., Land, S. M., \& Lee, E. (2014). Student-centered, open learning environments: Research, theory, and practice. In J. M. Spector, M. D. Merrill, J. Elen \& M. J. Bishop (Eds.), Handbook of research on educational communications and technology (pp. 641-651). New York, NY: Springer. https://doi.org/10.1007/978-1-4614-3185-5_51

Hazelkorn, E. (2011). Rankings and reshaping of higher education: The battle for world-class excellence. New York: Palgrave MacMillan. https://doi.org/10.1057/9780230306394

Healey, M. (2005). Linking research and teaching: Exploring disciplinary spaces and the role of inquiry-based learning. In R. Barnett (Ed.), Reshaping the university: New relationships between research, scholarship and teaching (pp. 67-78). Berkshire: Open University Press.

Holmes, R. (2013). Competition and controversy in global rankings. Retrieved from http://www.universityworldnews.com/article.php?story=20130626160718267

Horta, H. (2013). Deepening our understanding of academic inbreeding effects on research information exchange and scientific output: New insights for academic based research. Higher Education, 65(4), 487-510. https://doi.org/10.1007/s10734-012-9559-7

Horta, H., Sato, M., \& Yonezawa, A. (2010). Academic inbreeding: Exploring its characteristics and rationale in Japanese universities using a qualitative perspective. Asia Pacific Education Review, 12(1), 35-44. https://doi.org/10.1007/s12564-010-9126-9

Hu, Y.-L., Hung, G.-C., \& Ching, G. S. (2016). Looking into the research-teaching nexus in higher education. In Proceedings of THEIIER international conference: 2016 international conference on social science and economics (pp. 35-39). West Bengal, India: THEIIER.

Huang, M.-H., Chang, H.-W., \& Chen, D.-Z. (2006). Research evaluation of research-oriented universities in Taiwan from 1993 to 2003. Scientometrics, 67(3), 419-435. https://doi.org/10.1556/Scient.67.2006.3.6

Inanc, O., \& Tuncer, O. (2011). The effect of academic inbreeding on scientific effectiveness. Scientometrics, 88(3), 885-898. https://doi.org/10.1007/s11192-011-0415-9

Jaschik, S. (2012). Disappearing liberal arts colleges. Retrieved from https://www.insidehighered.com/news/2012/10/11/study-finds-liberal-arts-colleges-are-disappearing

Jaschik, S. (2014a). Non-decline of liberal arts colleges. Retrieved from 
Hu, Y.-L., Ching, G. S., \& Hung, C.-H.

https://www.insidehighered.com/news/2014/06/25/new-analysis-challenges-narrative-decline-about-libe $\underline{\text { ral-arts-colleges }}$

Jaschik, S. (2014b). The STEM enrollment boom. Retrieved from https://www.insidehighered.com/news/2014/04/07/study-finds-increased-stem-enrollment-recession

Jazvac-Martek, M., Chen, S., \& McAlpine, L. (2011). Tracking the doctoral student experience over time: Cultivating agency in diverse spaces. In L. McAlpine \& C. Amundsen (Eds.), Doctoral education: Research-based strategies for doctoral students, supervisors and administrators (pp. 17-36). Dordrecht: Springer. https://doi.org/10.1007/978-94-007-0507-4_2

Jonassen, D. H., \& Easter, M. A. (2012). Conceptual change and student-centered learning environments. In D. H. Jonassen \& S. M. Land (Eds.), Theoretical foundations of learning environments (2nd ed., pp. 95-113). New York, NY: Routledge.

Kao, C., \& Pao, H.-L. (2009). An evaluation of research performance in management of 168 Taiwan universities. Scientometrics, 78, 261. https://doi.org/10.1007/s11192-007-1906-6

Kezar, A., \& Sam, C. (2010). Understanding the new majority of non-tenure-track faculty in higher education: Demographics, experiences, and plans of action (Vol. 36). Hoboken, NJ: Jossey-Bass.

Land, S. M., Hannafin, M. J., \& Oliver, K. (2012). Student-centered learning environments: Foundations, assumptions and design. In D. H. Jonassen \& S. M. Land (Eds.), Theoretical foundations of learning environments (2nd ed., pp. 3-25). New York, NY: Routledge.

Longanecker, D. A. (2008). Mission differentiation vs mission creep: Higher education's battle between creationism and evolution. Retrieved from http://www.wiche.edu/info/gwypf/dal_mission.pdf

Luxbacher, G. (2013). World university rankings: How much influence do they really have? Retrieved from https://www.theguardian.com/higher-education-network/blog/2013/sep/10/university-rankings-influenc e-government-policy

McLachlan, G. J. (2004). Discriminant analysis and statistical pattern recognition: Wiley Interscience.

Parry, S. (2007). Disciplines and doctorates. Dordrecht: Springer.

Scearce, C. (2008). Adelard's questions and Ockham's razor: Connections between medieval philosophy and modern science. Retrieved from http://www.csa.com/discoveryguides/medieval/review4.php

Schiewer, H.-J., Jehle, C., \& Maes, K. (2014). Tenure and tenure track at LERU universities: Models for attractive research careers in Europe. Leuven, Belgium: LERU.

Smyth, R., \& Mishra, V. (2014). Academic inbreeding and research productivity and impact in Australian law schools. Scientometrics, 98(1), 583-618. https://doi.org/10.1007/s11192-013-1052-2

Stock, W. A., Siegfried, J. J., \& Finegan, T. A. (2011). Completion rates and time-to-degree in economics phd programs. The American Economic Review, 101(3), 176-193. https://doi.org/10.1257/aer.101.3.176

Subramaniam, M., Perrucci, R., \& Whitlock, D. (2014). Intellectual closure: A theoretical framework linking knowledge, power, and the corporate university. Critical Sociology, 40(3), 411-430. https://doi.org/10.1177/0896920512463412

Tartari, V., Salter, A., \& Este, P. D. (2012). Crossing the rubicon: Exploring the factors that shape academics' perceptions of the barriers to working with industry. Cambridge Journal of Economics, 36(3), 655-677. https://doi.org/10.1093/cje/bes007

Tavares, O., Cardoso, S., Carvalho, T., Sousa, S. B., \& Santiago, R. (2014). Academic inbreeding in the Portuguese academia. Higher Education, 69(6), 991-1006. https://doi.org/10.1007/s10734-014-9818-x

Teichler, U., Arimoto, A., \& Cummings, W. K. (2013). The changing academic profession. Dordrecht: Springer. https://doi.org/10.1007/978-94-007-6155-1

Trow, M. (1974). Problems in the transition from elite to mass higher education. In OECD (Ed.), Policies for higher education (pp. 51-101). Paris: OECD.

Vincent-Lancrin, S. (2008). The reversal of gender inequalities in higher education: An on-going trend. In Higher education to 2030 - Volume 1: Demography (pp. 265-298). Paris: OECD.

Wen, T.-S., Ching, G. S., \& Tang, C.-W. (2013). Realities in scholarly publication trends: A case study of a social science university in Taiwan. International Journal of Research Studies in Education, 2(2), 31-42. https://doi.org/10.5861/ijrse.2012.146 